menstrual history. However, we frequently rely on such a calculation when deciding whether an intrauterine device (IUD) can be fitted as an emergency contraceptive. Maybe in light of the evidence supplied in their letter this practice should be reviewed? If we accept that menstrual history can be used to guide the timing of ovulation in relation to EC, then recognising the significant cost differential between UA and levonorgestrel and UA's proposed superior ability to delay/inhibit ovulation, maybe there is an opportunity to use UA 'smarter' around the proposed time of ovulation when an IUD is declined.

Graham Davies, FRCOG, MRSRH

Consultant in Sexual Health, Sexual Health Services, NHS Solent Healthcare, St Mary's Hospital Community Campus, Portsmouth, UK; graham.davies@solent.nhs.uk

Competing interests None.

J Fam Plan Reprod Health Care 2013;39:61.

doi:10.1136/jfprhc-2012-100519

\title{
REFERENCES
}

1 Webb A, McGough P, Melvin L. Pitfalls of adapting emergency contraception CEU guidance. J Fam Plan Reprod Health Care 2012;38:270

2 Faculty of Sexual and Reproductive Healthcare. Emergency Contraception. 2011. http://www.fsrh.org/pdfs/ CEUguidanceEmergencyContraception11.pdf [accessed 16 October 2012].

\section{Ulipristal acetate emergency contraception}

I read with interest the letter by Webb et al. ${ }^{1}$ about the pitfalls of adapting the Clinical Effectiveness Unit's guidance on emergency contraception (EC). ${ }^{2}$ Their letter discusses, in relation to maximising the pharmacodynamic attributes of ulipristal acetate (UA), the significant inaccuracies inherent in the calculation of the timing of ovulation based on the 